\title{
BASIC INTERACTIONS OF Aspergillus niger WITH Se(IV)
}

\author{
MARTIN URÍK ${ }^{1}$, JAROSLAV ŠEVC ${ }^{1}$, PAVOL LITTERA ${ }^{1}$, \\ MAREK KOLENČÍK ${ }^{1}$, SLAVOMÍR ČERŇANSKÝ ${ }^{2}$ \\ ${ }^{1}$ Geological Institute, Faculty of Natural Sciences, Comenius University in Bratislava, \\ Mlynská dolina, Bratislava, SK-842 15, Slovak Republic (urik@fns.uniba.sk) \\ ${ }^{2}$ Department of Ecosozology and Physiotactics, Faculty of Natural Sciences, \\ Comenius University in Bratislava, Mlynská dolina, Bratislava, SK-842 15, \\ Slovak Republic
}

\begin{abstract}
Filamentous fungus Aspergillus niger is commonly found on decaying vegetation or in indoor environment and has a number of uses, including application in bioremediation. Hence, the basic interactions of this common mould with selenite were studied, including biovolatilization, bioaccumulation and toxicity effects of selenite on fungal growth. The fungal strain, originally isolated from noncontaminated soil, was cultivated under aerobic conditions on liquid cultivation media with concentration of Se(IV) 19 or $27 \mathrm{mg} . \mathrm{l}^{-1}$ during 25 days. The fungal growth in the presence of selenite was not inhibited when compared to control, only the sporulation was reduced. The concentration of Se(IV) in liquid medium decreased rapidly within first ten days to $1 \mathrm{mg} \cdot \mathrm{l}^{-1}$. However, according to results from the $25^{\text {th }}$ day of cultivation, the concentration of total selenium in medium did not change significantly and only negligible amount of selenium (less then $1 \%$ ) was bioaccumulated. That indicates some biotransformation of selenite into other selenium species. During the cultivation, up to $21 \%$ of total amount of selenium was transformed into volatile derivatives (biovolatilization) by filamentous fungus $A$. niger.
\end{abstract}

Key words: selenite, filamentous fungi, biovolatilization, bioaccumulation

\section{Introduction}

Selenium is an essential micronutrient in animals. However, its elevated concentrations may result in toxic effects (EISLER, 2000). Hence, environmental pollution with selenium mobilized from geological sources as a result of industrial or agricultural activities may be serious threat for ecosystems (DAVIS et al., 1988).

Bioremediation, including biosorption, bioaccumulation and biovolatilization is an alternative promising technology for removal of toxic metals from soils and waters (HILLER et al., 2008; PIPÍŚKA et al., 2008). Biovolatilization of selenium by microorganisms, including fungi, has received much attention because of its application in bioremediation of selenium contaminated soils or waters (THOMPSONEAGLE and FRANKENBERGER, 1992). This process is realized via methylation pathway, where the selenium oxyanions are reduced, and the elemental selenium can be produced, a process which also results in detoxification (GADD, 1993).

Despite fungal capability to biovolatilize selenium, it is need to be known how does the fungi react on elevated concentrations of bioavailable selenium species, especially selenite, which is scavenged from waters to a greater extent then selenate (HAMILTON, 2004). 
The objective of this study was to evaluate selenite uptake and transformation into volatile derivatives by Aspergillus niger and the fungal growth responses to elevated selenite concentrations during cultivation.

\section{Materials and methods}

The strain of Aspergillus niger used in this study was originally isolated from non-contaminated soil and was maintained on agar medium under laboratory conditions. Fungal inocula were prepared from 14-day old cultures of this strain.

The stock solutions of selenite were prepared in deionized water from $\mathrm{Na}_{2} \mathrm{SeO}_{3} .5 \mathrm{H}_{2} \mathrm{O}$ (Merck, Germany).

The cultivation system for experimental purposes included $15 \mathrm{~mL}$ of Sabouraud cultivation media (HiMedia, Mumbai, India), $5 \mathrm{~mL}$ of prepared fungal inocula and $5 \mathrm{~mL}$ of stock solutions to reach concentration 19 or $27 \mathrm{mg} . \mathrm{l}^{-1}$ of $\mathrm{Se}$ (IV) in cultivation system. Selenite free control was also set up and monitored for 25 day. The $\mathrm{pH}$ of cultivation media, weight of dried biomass and concentration of Se(IV) in medium were determined on $5^{\text {th }}, 10^{\text {th }}, 15^{\text {th }}, 20^{\text {th }}$ and $25^{\text {th }}$ day of cultivation. On $25^{\text {th }}$ day the concentration of total selenium in biomass and cultivation media was determined. All experiments were preformed in triplicate.

\section{Results and discussion}

Growth of Aspergillus niger in absence of selenite is illustrated in Fig. 1. There is a linear growth phase in first 5 day of cultivation, followed by decline phase. On the $5^{\text {th }}$ day the dry weight of biomass reached its maximum $(0.36 \mathrm{~g})$. Surprisingly, the declination phase in presence of selenium (Fig. 1) is not so evident comparing to the control.

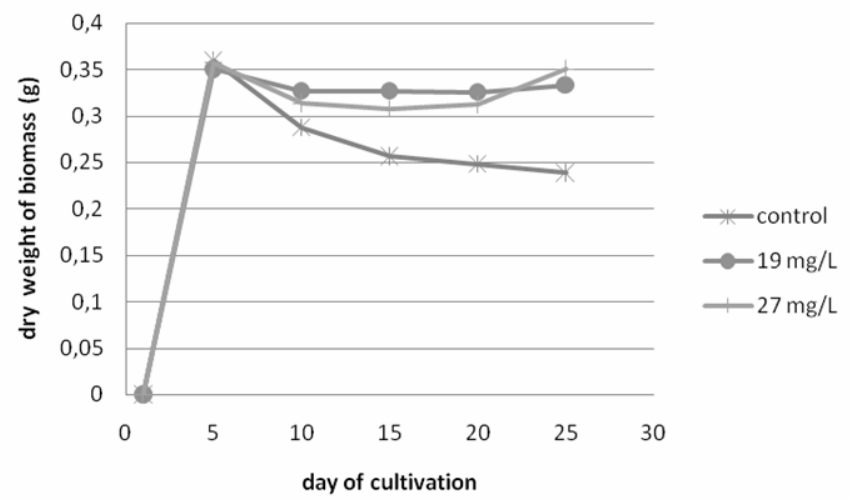

Fig. 1. Changes in weight of dry biomass during cultivation of Aspergillus niger in absence (control) or presence of selenite with different initial concentration (19 or $\left.27 \mathrm{mg} . \mathrm{L}^{-1}\right)$.

The first phase is followed by relative stationary phase until the $25^{\text {th }}$ day of cultivation. The maximum dry weight of biomass is almost the same for the control 
and growth of $A$. niger in presence of selenite. However, the presence of selenite significantly reduced sporulation of the fungus. These observations suggest the relative resistance of $A$. niger to high selenium concentrations. Generally, filamentous fungi are resistant to high levels of metals and metalloids, which indicates the potential of fungi as bioremeditation agents (IRAM et al., 2009).

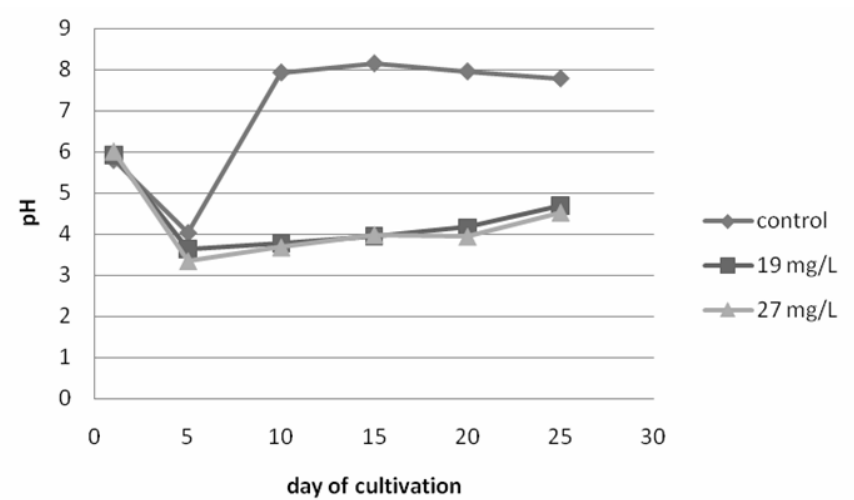

Fig. 2. Changes in $\mathrm{pH}$ of cultivation media during cultivation of Aspergillus niger in absence (control) or presence of selenite with different initial concentration (19 or $\left.27 \mathrm{mg} . \mathrm{L}^{-1}\right)$.

The initial $\mathrm{pH}$ of the cultivation media in absence of selenite was around 5.8 and decreased to 4.03 in first days of cultivation (Fig. 2), followed by rapid increase to 7.92 determined on the $10^{\text {th }}$ day of cultivation. The $\mathrm{pH}$ of the liquid medium did not significantly change until the end of experiment. The changes in $\mathrm{pH}$ value of cultivation media in presence of selenite (Fig. 2) were significantly different compared to control. After initial decrease (3.6 and 3.4 for cultivation systems with initial Se(IV) concentration of 19 and $27 \mathrm{mg} .1^{-1}$, respectively), the $\mathrm{pH}$ value only slightly increased with time up to approximately 4.6 for both initial concentrations of selenite. The decrease in $\mathrm{pH}$ of liquid medium during cultivation of white-rot fungus Phanerochaete chrysosporium in presence of heavy metals was published by FALIH (1997), who claims, the decrease in $\mathrm{pH}$ is unfavorable condition for the fungus, probable because of increasing solubility of metals in the medium. In recent experiment, the $\mathrm{pH}$ and metabolic activity of fungus should significantly affect selenium toxicity, its ionic forms and mobility.

During the initial growth rate decreased the concentration of Se(IV) rapidly by more than $50 \%$ and later to 1.07 and $1.26 \mathrm{mg} \cdot \mathrm{l}^{-1}$ at the end of the $10^{\text {th }}$ day of cultivation for systems with initial concentration of Se(IV) 19 and $27 \mathrm{mg}^{-1}$, respectively (Fig. 3). The concentration of selenite in cultivation media steadily decreased with time. However, the concentration of total selenium should not be changed during the cultivation. The Table 1 shows the results of total selenium in media and fungal biomass at the end of cultivation, on the $25^{\text {th }}$ day. The concentration of total selenium in cultivation medium decreased only slightly suggesting possible transformation of Se(IV) into different chemical species. Biomass-associated transformation of selenite (e.g. reduction to amorphous elemental selenium) has been 
published previously (TOMEI et al., 1992). According to differences in amount of added $\mathrm{Se}(\mathrm{IV})$ and the sum of Se(IV) in biomass and medium, it is evident that the total selenium mass balance has change during the cultivation period.

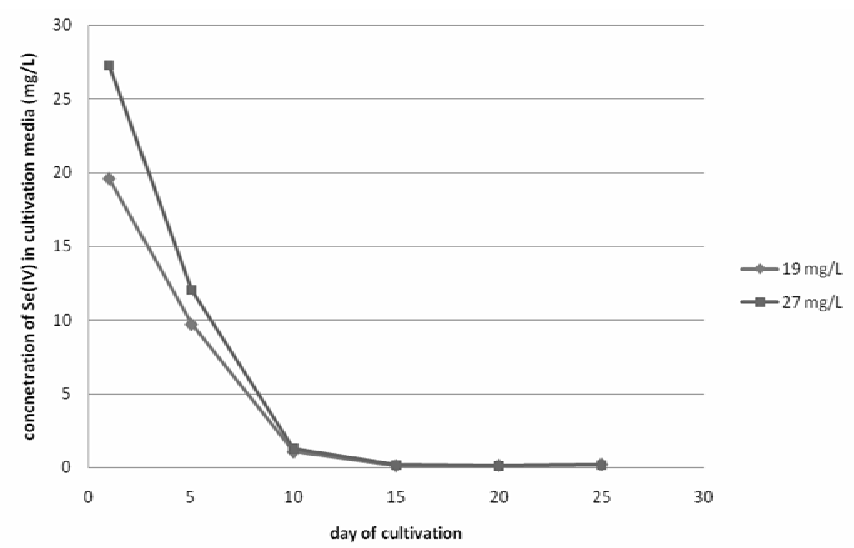

Fig. 3. Changes in Se(IV) concentration in cultivation media during cultivation of Aspergillus niger in presence of selenite with different initial concentration (19 or $\left.27 \mathrm{mg} . \mathrm{L}^{-1}\right)$.

Table 1. The amount of total selenium in biomass and cultivation media on the $25^{\text {th }}$ day of cultivation with calculated amount of biovolatilized selenium during cultivation.

\begin{tabular}{|c|c|c|c|}
\hline $\begin{array}{c}\text { Initial } \\
\text { concentrations of } \\
\text { Se(IV) } \\
\left(\text { mg.L }^{-1}\right)\end{array}$ & $\begin{array}{c}\text { Concentration of } \\
\text { total selenium in } \\
\text { medium } \\
\left(\mathrm{mg.L}^{-1}\right)\end{array}$ & $\begin{array}{c}\text { Concnetration of } \\
\text { total selenium in } \\
\text { biomass } \\
\left(\mathrm{mg}^{\mathrm{mg}} \mathrm{kg}^{-1}\right)\end{array}$ & $\begin{array}{l}\text { Amount of } \\
\text { biovolatilized } \\
\text { selenium } \\
(\%)\end{array}$ \\
\hline 19 & 17.790 & 1.351 & 8.89 \\
\hline 27 & 21.355 & 1.309 & 21.58 \\
\hline
\end{tabular}

The loss of selenium in cultivation system represents approximately $8.9 \%$ and $21.6 \%$ for system with initial concentration of Se(IV) 19 and $27 \mathrm{mg} . \mathrm{l}^{-1}$, respectively. The amount of accumulated selenium in biomass was negligible, less than $1 \%$ of total selenium present in cultivation system. Previously, it was demonstrated that Penicillium sp. is capable of selenite transformation in aqueous medium by biomass associated process as well as the formation of volatile organic derivatives (BRADY et al., 1996).

\section{Conclusions}

1. The weight of dry biomass was not significantly different during the cultivation in presence and absence of Se(IV) (19 or $\left.27 \mathrm{mg} . \mathrm{l}^{-1}\right)$ in cultivation media.

2. When comparing to control, the $\mathrm{pH}$ value of cultivation media in presence of selenite maintained in acidic region of $\mathrm{pH}$ (around 4), while the $\mathrm{pH}$ value of media in absence of selenite rapidly increased up to $\mathrm{pH} 8$.

3. The concentration of Se(IV) decreased rapidly within 10 days of cultivation. However, the concentration of total selenium decreased only slightly suggesting 
possible transformation of Se(IV) into different chemical species.

4. While the accumulation of selenium after 25-day cultivation was negligible, the almost all of uptaken selenium was transformed into volatile derivatives (up to $21 \%$ ) or chemical species other than selenite (according to previous statement).

Acknowledgements: This research was supported by VEGA 1/4361/07.

\section{References}

BRADY, J.M., TOBIN, J.M., GADD, G.M.: Volatilization of selnite in aqueous medium by a Penicillium species. Mycol. Res., 100, 1996, 955-961.

DAVIS, E.A., MAIER, K.J., KNIGHT, A.V.: The biological consequences of selenium in aquatic ecosystems. Calif. Agr., 42, 1988, 29.

EISLER, R. Selenium. In: Handbook of Chemical Risk Assasment: Health Hazards to Humans, Plant and Animals. Lewis Publishers, CRC Press, Boca Raton, 2000, 1649-1705.

FALIH, A.M.: Influence of heavy-metals toxicity on the growth of Phanerochaete chrysosporium. Bioresour. Technol., 60, 1997, 87-90.

GADD, G.M.: Interactions of fungi with toxic metals. New Phytol., 124, 1993, 25-60.

HAMILTON, S.J.: Review of selenium toxicity in aquatic food chain. Sci. Total. Environ., 326, 2004, 1-31.

HILLER, E., JURKOVIČ, L, BARTÁL, M.: Effect of temperature on the distribution of the polycyclic aromatic hydrocarbons in soil and sediments. Soil Wat. Res., 3, 2008, 231-240.

IRAM, S., AHMAD, I., STUBEN, D.: Analysis of mines and contaminated agricultural soil samples for fungal diversity and tolerance to heavy metals. Pak. J. Bot., 41, 2009, 885-889.

PIPÍŠKA, M., HORNÍK, M., VRTOCH, L., AUGUSTÍN, J., LESNÝ, J.: Biosorption of Zn and Co ions by Evernia prunastri. Chem. Ecol., 24, 2008, 181-190.

THOMPSON-EAGLE, E.T., FRANKENBERGER, W.T.: Bioremediation of soils contaminated with selenium. Adv. Soil Sci., 17, 1992, 262-310.

TOMEI, F.A., BARTON, L.L., LEMANSKI, C.L., ZOCCO, T.G.: Reduction of selenate and selenite to elemental selenium by Wolinella succinogenes. Can. J. Microbiol., 38, 1992, 1328-1333. 